DOI: 10.1515/ausfm-2015-0014

\title{
The Draughtsman's Contract and the Crisis of Structuralism
}

\author{
Paul H. Fry \\ Yale University (New Haven, USA) \\ E-mail: paul.fry@yale.edu
}

\begin{abstract}
Peter Greenaway's cinema questions the numerical, verbal and pictorial determinations of sets and systems. Two or one, even or odd? (Twelve drawings or - thirteen?) Is two, as a stabilization of symmetry, undermined by decompositions in time and space that defy any possible reduction to sub-binaries? This latter question is reserved mainly for $A$ Zed and Two Noughts (1985), though it is anticipated in Vertical Features Remake (1978) and especially The Draughtsman's Contract (1982), which I will treat as a response to both questions at once. The plot of this film, with its riderless horses and lack of an heir, raises the question Lévi-Strauss raised in the most influential exposition of structuralism we have, The Structural Study of Myth. Two or one? Are we born of parents or are we autochthonous? Lévi-Strauss's reading of the Oedipus myth is an allegory of structuralism itself: are intelligible signs born from the differentiation of two other signs (binaries) or do they arise parthenogenetically, as "natural signs," from the autonomous self-identity of what they represent? On the other hand, in the dissolution of identity we see in the body of Mr. Herbert raised from the moat, are there appearances that dissolve identity altogether? The paper will show how the overdetermined frame and its symmetries the stationary camera, the draughtsman's viewfinder and grid, the "framing" of Mr. Neville, etc.) are confirmed and disconfirmed by invasions of the frame, and the ways in which drawing, painting, and landscaping both "fix on paper" and disrupt the offspring or sterility of twinning.
\end{abstract}

Keywords: structuralism, structuralist film, Peter Greenaway, systems, symmetry, framing.

Everyone, including Peter Greenaway himself, says that his early work is an encounter with structuralism. Many let it go at that, but Greenaway insists too that this early work is a critical response to structuralism, a critique of systems and system-making that revels nonetheless in the encyclopedic shape-shiftings and overlaps of cinematic, verbal, musical, painterly and numerical language systems. In speaking of systems, as Greenaway often also does, I seem to have brought us 
forward to the theoretical present, to the work of Niklas Luhmann and others. Henry Sussman has made this move in discussing The Pillow Book of 1996. But we have to do here with cinematic work that spans the period 1978-1985.

The Draughtsman's Contract, which is not without an Oedipal storyline, is often understandably called a structuralist film (with Greenaway's approval), typically without pausing to consider the premises and methods of structuralism; but it is also, with all Mrs. Talmann's irony about "significance," a critique of structuralism. Besides The Draughtsman's Contract of 1982, I have chiefly in mind two of the experimental pseudo-documentaries, Vertical Features Remake (1978) and The Falls (1980), together with the feature film that follows Draughtsman, A Zed and Two Noughts (1985). For this period we must assume that words like structure and system arise both from the anthropological and linguistic structuralism of Lévi-Strauss with Jakobson and from the film theory of Christian Metz and his contemporaries, doubtless including British refugees from literary study like Stephen Heath. To this constellation we should add, in the spirit of critique insisted on by Greenaway, the early work of Derrida, especially the epochal 1967 critique of Lévi-Strauss, Structure, Sign and Play in the Discourse of the Human Sciences.

But this roll call still does little to overcome our prevailing vagueness when we speak of Greenaway and structuralism. In this paper I want to describe what the evidence of the films themselves suggests to be the structuralism Greenaway has in mind, and in so doing I must begin by insisting that a certain form of structuralism, extremely influential in cinema and cinema theory, is only partially in play, though it is certainly involved. By this I mean the psychoanalytic structuralism mediated by Lacan. The agenda for a structuralist account of "the language of film" in the period immediately preceding the Greenaway films I have mentioned is laid out by Christian Metz, especially in The Imaginary Signifier, written between 1973 and 1976 and soon translated. For Metz, the central structuralist concept for understanding cinematic language as a quasiunconscious system was Lacan's alignment of condensation and displacement in the Freudian dreamwork with the rhetorical terms metaphor and metonymy, terms that Lacan found characterizing the two types of aphasia in the essay on the aphasias by Roman Jakobson. Even though Metz rigorously criticizes the imperfect overlap between these pairings, together with the imperfect overlap between the pairings metaphor/metonymy and paradigmatic/syntagmatic within Jakobson's system itself, Metz builds his own system on these pairings and finds in their very imperfection a measure of freeplay, an elusiveness evocative of unconscious thought, in the language of cinema. 
In my opinion, however, while important, this is not the account of structuralism that matters most to Greenaway. He is still more interested in the temptations offered by structures that seduce waking consciousness, granting that unconscious structures may superimpose themselves on the attempts at scientific objectivity that obsess the male protagonists in most of his films. I shall soon try to say how this preoccupation directs Greenaway's emphasis in dialogue with structuralism, but I should anticipate here the way in which even for him, despite his undoubted belief that Freud could pose as one of the cranks who populate his films, there remains an underlying problem - call it the anthropological unconscious - which has to do with inheritance, a theme obviously central to The Draughtsman's Contract and one that inescapably takes an Oedipal form: What determines paternity, who is the father that is killed and by whom, and why does this sacrifice repeat itself across generations? Lurking in these questions you can find the plot of The Draughtsman's Contract.

In this form, then, the psychoanalytic perspective remains, but it presents itself in Greenaway's playful structures as an experiment with intermedial languages, perhaps indeed not unlike what Freud and Lacan after him call the rebus in the dreamwork, or what the anti-Freudian Deleuze calls multiple plateaus: that is, the way in which an unconscious thought or even a conscious one, as typically in Greenaway's film language, can be comprised of verbal, visual, musical, and numerical signs mixed up together - and also of course, in the case of film, of both static and moving images. Greenaway in his recent defences of an anti-narrative cinema has spoken perhaps too emphatically about the inferiority of image-based narrative to spoken or written verbal narrative. The sentence "The girl looked out of the window" properly leaves a great deal to the imagination, he says, whereas film needs to frame the girl, like the window itself: to describe her appearance, her expression, and what she sees all at once in ways that imprison both her and the spectator-like a zoo, or a system. But in the actual working out of Greenaway's films, as Brigitte Peucker (2014) has shown, this contrast between the visual and the verbal is too neat. Especially in The Draughtsman's Contract, as she says, the exuberant freeplay of verbal metaphor borrowed from English Restoration Comedy offsets and liberates the self-conscious and self-critical enframings of the draughtsman's grid, together with the film's symmetries and the fixed camera positions without zooms or tracking. Music in the meantime obtrudes its own code. The manifest structure of a Greenaway film, then, in one way or another, is like a rebus.

So what do I think Greenaway means by "structuralist" when he accepts that adjective in accounts of his work and willingly repeats it? I think that what he 
means arises from the Saussurian premise that the binary is the foundational principle of semiotics, especially as this premise works itself out in the structural anthropology of Lévi-Strauss, and yet more especially in the famous chapter on "the structural study of myth," which features Lévi-Strauss's confessedly amateur and unguardedly anti-Freudian interpretation of the Oedipus myth. As he spreads out his rows and columns concerning key events and recurrent symbols in all the versions of the myth he has ready to hand, Lévi-Strauss argues that the underlying question answered by this myth, as indeed by all myth, is the question "two or one?" Are we born of one parent, as in parthenogenesis or autochthony, or are we born rather of two parents? "Madam," says Mr. Neville in Draughtsman to Mrs. Talmann, "[the child Augustus] is an 'orphan' because his mother became a Catholic?" Is every exogamous birth among these intolerant Protestants a false virgin birth? Mythical thinking posits that we are natural signs, representing by reproducing the unique thing that gives rise to us, in keeping with positivist linguistic theories: the name Adam means "red clay," the name Oedipus means a foot swollen by the clay still sticking to it, both heroes having been born from the earth in Eden and on Mount Cithaeron, respectively. In short, born from one.

Needless to say - but it just is not clear, at least to me, how fully Lévi-Strauss is aware of this himself - this reading of birth myths, or reproduction myths as we may more pointedly say of medial systems, not only reconfirms the repudiated version of Freud, the father Lévi-Strauss kills off in proclaiming his own science, but is also an allegory of structuralism itself. Scientific meaning understood as the truth of structuralist science is born of the difference between two arbitrary signs (what coupling could be more arbitrary than Jocasta and Oedipus, who produce the truth between them?), whereas mythic meaning - positivism's myth of natural signs - entails a sign born directly from its object. Something like what I have just outlined would be Lévi-Strauss's allegory, but by the time of Greenaway the birth myth of structuralism opposes itself not only to positivism - and also to Whorfian pragmatist theories of the sign discussed by the mad linguists of The Falls but also by the uncontrollable dissemination or monstrous birth of the sign that Derrida called an "event" in the essay I have mentioned, and that we have since called deconstruction. Born from one or born not from two but from everything, everything interconnected yet beyond the remotest conceivable horizon of order, the encyclopedia gone mad: at the meeting extremes of indivisible unity and what the languages of $A$ Zed and Two Noughts would call decomposition. The one and the shapeless many are the evil twin enemies of the science of structuralism. I shall be returning to these dangerous extremes in conclusion. 
As I now get down to cases, my paper will turn out to be about the number 11, a double "vertical feature" that can produce the number two, either by addition or in Roman numerals, or can be the two verticals we visualize as twins, or can begin an infinite series (one, one, etc., in perpetuity), or can graphically express binarism (this alongside that vertical) - or perhaps can represent the doubling of the psychoanalytic ur-signifier, misleadingly represented to consciousness as the I of the ego but really doubling the ego as the name of the father, the vertical form that Lacan for obvious reasons calls the phallus.

So it's time for our elevenses. In The Draughtsman's Contract there unexpectedly appears a ladder - leaning against the house, leading up to the window behind which one of the trysts occurs, and later said to be used mainly for "the collecting of apples." This ladder appears as a mist rises, one of three mists in the film, the riderless white horse emerging from the second and Mr. Neville, the draughtsman returning from Radstock emerging from the third. Mr. Neville, who hates any change in what he sees, decides even so to put the ladder in his drawing, though he derisively calls it a "meretricious vertical," still being at this point in the film an enemy of interpretation. A cigar is only a cigar. More or less in agreement here, the brilliant Sarah Talmann, who is the epicenter of the film's wit and impresario of its conspiracies, describes her husband's "long white britches" as a meretricious vertical when she goes on to say that they contain "nothing of substance," a problem that complicates the possibility of birth and inheritance for the estate. "Woman, it takes two!" says her husband. "It does indeed, sir." It is she, too, here teetering toward Lacan, who ironically parries and parodies Mr. Neville's boastful wordplay about his phallic "significance." She has said that as she moves away from the house she feels that she lessens in significance, self-consciously aware, as she always is, of her decreased commodity value in relation to property as the prospect of a son's inheritance decreases. With comparative naivety passing for libertine wit, Mr. Neville responds, "what signifies does not grow smaller for me," a double entendre that of course entirely suits Mrs. Talmann's knowing confinement of significance to inheritance only. No male heir, no property, no significance. In any case the ladder in question, which has appeared less prominently against a white wall toward the end of Vertical Features Remake, of course does have rungs as well as verticals. They are what bind the binary, for example completing the letter $\mathrm{H}$ in the titles of Greenaway's experimental films leading up to Vertical Features, $H$ Is for House and A Walk Through $H$. As Greenaway explained in his account of Vertical Features, the horizontal is indispensable in making a grid, the rectangle that constitutes any and all frames and horizons. 
But the Greenaway ladder, I would argue, is first and foremost an eleven. This number qua number makes a lone anecdotal appearance in Draughtsman. It is the number of trees planted by a Mr. Lucas to commemorate the birth of his eleven children - nearly all of whom, but not all, died in childbirth or infancy. The eleven trees, which thus fail to bear fruit, as it were, are given the names, or signifiers, of the children, not of the species identity that destines them, from one seed, to be what they are. Hence they are purely arbitrary signs, barren of identity or intrinsic meaning. There are twelve drawings in the contract, not eleven, until the fatal thirteenth is attempted, and we may say not only that despite its symmetry as an even number (there are two sets of six drawings), 12 is itself dangerously in excess of the structuralist equipoise marked by 11; it is also a false binary, an illusion of symmetrical completeness like so much else in the film, especially the ubiquitous and commonplace black-and-white binary of the drawings themselves and of the costuming. Mr. Neville has been hired to "fix Mr. Herbert's estate in black and white," to fix it in place devoid of birdsong and the drift of animals. The number 12 after all does not implicitly contain the mystery of 2 or 1 but poses the mystery openly as a question -1 or 2 ? - which seems progressive rather than symmetrical: from 1 to 2 , and so on forward. The introduction of 3 in 13 is not only unlucky but introduces an excess to the mystery itself: to produce an heir at Compton-Anstey, a third has been scandalously needed, with Neville, a name containing 11 in its two l's, supplementing Talmann, a name that would mean tall man in English only if it had two l's. Mr. "new evil 11" is punished for his exogamous paternity, "never ill" until now but about to be "null," blinded before he dies like Oedipus before him.

Graphically, the number 11 is a twin towers, like the empty Eiffel Tower from which the horizon organizes itself as described by Roland Barthes in Le tour Eiffel (1989) or the twin towers of New York as described long before 2001 by Michel de Certeau (1984) as an empty principle, mimicking the vertical, paradigmatic axis in Jakobson's Linguistics and Poetics (1960), that organizes the horizontal, syntagmatic city at its feet. Naturally enough, such structures are everywhere in Vertical Features Remake. The water tower to the right of another, narrower tower in a recurrent image is where, in a signature mise en abîme, Greenaway's alter ego Tulse Luper - a name with two l's - has stored the footage that the pseudo-scholars described in the voice-over are trying to reconstruct for this film. This shot turns up again repeatedly in The Falls, where the water tower is once again identified as a film archive. These towers with their life-giving waters store in their virtual vertical space the signifiers that compose themselves on the 
horizontal axis of composition, according to structuralism. As Jakobson famously put it, the poetic function transfers the principle of equivalence from the axis of selection to the axis of combination. You can never actually ascribe substance or content to the vertical axis of selection from which structure emanates any more than you can directly study the unconscious. The event or advent of structure emerges from what is truly an empty, meretricious vertical.

But to come closer to 11: each of the four remakes in Vertical Features consists of eleven sets of eleven counted segments of footage representing manmade and natural verticals, although this division becomes more and more obscure with each remake, with tendencies to lose count, with the replacement of counting by the composer Michael Nyman's increasingly complex percussive score (which is still however dominated by twice-repeated chords), and so on. The significance of this number seems to disappear in The Falls, which consists of ninety-two brief pseudo-biographical studies of victims of "V-U-E," the "violent unknown event" - "that which is seen" in the French behind the acronym, "vue," as opposed to that which is known. As Greenaway has often said, Mr. Neville's problem in Draughtsman focuses on the difference between what is known and what is merely seen, and in the film Mrs. Talmann repeats this in mockery of Mr. Neville. The surname of all ninety-two victims of the V-U-E, taken from a directory, begins with the letters "f-a-l-l." But wait, there it is, the number 11 in the letters "l-1," attached rebus-like now by a musical note, fa, to the fall which characterizes many of the violent unknown events caused by the revenge of birds against being caged by vertical bars in human thought and practice: "falls" as a word being a slight evasion of the word "phallus" but also a slight evasion of the word "false" - and, of course, as an event, evoking the repeated falls of man, constantly repeating the link with the apples that the ladder in Draughtsman is used to pick. In A Zed and Two Noughts, the apple is the first object to decompose in time-lapse photography.

The two ones in 11 are twins, rendered identical however only by artifice or obsessiveness - by a structure into which they are inserted. In A Zed and Two Noughts, the twins Oliver and Oswald Deuce (two O's or zeros masquerading as ones or identities) look quite different from each other at first, light-haired and dark-haired, dressed differently, reacting to grief at the loss of their wives in seemingly different ways, but in the long run their obsessively shared activities make them identical, and we often see them side by side, like 11, like the bars of animal cages, like the curtains framing the bed of Alba, whose personal symmetry can be restored only by the loss of a second leg after the first. The 
twins of Draughtsman, the Poulencs, are structurally at least as important as the Deuces, though their marginal presence in the screenplay seems meretricious. They appear first during the credits, later at the top of the stairs in the house, but do nothing on which the plot turns until their final appearance, when it is they who kill Mr. Neville, each using a straight white cudgel resembling a one or an 1 to deliver alternating blows. Having stood outside the narrative frame, they now slide under it. But beforehand, they have not only been an 11, dressed in matching white and always speaking and gesturing in sympathy, which made them uncannily one - that is part of the lore of twins - but their double vertical is also repeated twice within themselves, first in the double-peaked wigs that Greenaway seems more or less to have invented for this film's cast, and second in the twin peaks of the blood-red lipstick each of them wears. They are examples, in short, of the binary subsets, with one always becoming two at a new level, which Roland Barthes describes as the principle of narrative in The Structural Analysis of Narrative (1977). Each of their names contains one l, but together they are 11, and also hell. Vamping gay mannerisms like their namesake the composer Poulenc, they are two similar ones who do not reproduce.Prominently in Greenaway's experimental films, fleetingly in various feature films, and again in the recent intermedial extravanganza, Tulse Luper Suitcases, Greenaway's alter ego Tulse Luper has an evil twin, Van Hoyten. In Draughtsman, Van Hoyten is the name of the Dutch landscape architect who by the time of Mr. Neville's return from Radstock has come from The Hague to install himself on the estate not as a draughtsman but as an improver, and he appears to have installed himself as though he were Mr. Neville in Mrs. Talmann's libidinal economy. Mr. Neville is now dressed in white, having been in black during his Compton-Anstey sojourn in contrast with all the other principal characters in white, and Van Hoyten is in black similar to what Mr. Neville formerly wore. When we first see these twins alongside each other with Mrs. Talmann, we realize that they look very much alike. They are the structuralist twin and the anti-structuralist twin. Mr. Neville fixed the estate in black and white, while Van Hoyten introduces fluidity by proposing to flood the lower grounds, prompting Mr. Neville to wonder, ironically but nervously, whether he proposes to join Anstey to the sea - clearly in defiance of all framing. It is always animals and the human being hired to be a garden god who violate frames and destabilize verticals, as when the garden god removes an obelisk from its pedestal, replaces it with himself, and urinates a diagonal line. When in the end this garden god lowers himself from the equestrian statue by the moat where Mr. Herbert's body was found and where the dead Mr. Neville has 
now been tossed, we must wonder whether, in the deconstructed frame of things, the centaur-like detachment of mind from body we have witnessed throughout the film retains anything like the stability that belongs to human structures. After all, even when Mr. Herbert's body was pulled out of the moat, his bronze effigy still rode the bronze horse. What happened to it on the evening of Mr. Neville's death? Did the garden god put the sign of the father wherever it was that he had put the obelisk?

\section{References}

Barthes, Roland. 1977 [1966]. Introduction to the Structural Analysis of Narratives. In Image - Music - Text, 32-51. New York: Hill and Wang.

Barthes, Roland and André Martin. 1989. Le tour Eiffel. Seuil: Centre National de la Photographie.

de Certeau, Michel. 1984. Walking in the City. In The Practice of Everyday Life, 102-118. Berkeley: University of California Press.

Derrida, Jacques. 1967. La structure, le signe et le jeu dans le discours des sciences humaines [Structure, Sign, and Play in the Discourse of the Human Sciences]. In L'écriture et la différence [Writing and Difference], Jacques Derrida, 409429. Paris: Éditions du Seuil.

Jakobson, Roman. 1960. Linguistics and Poetics. In Style in Language, ed. Thomas Sebeok, 350-377. Cambridge, Massachusetts: MIT Press.

Lévi-Strauss, Claude. 1963 [1958]. The Structural Study of Myth. In Structural Anthropology, 206-231. New York: Basic Books.

Metz, Christian. 1982 [1977]. The Imaginary Signifier. Psychoanalysis and the Cinema. Bloomington and Indianapolis: Indiana University Press.

Peucker, Brigitte. 2015 [1997]. Incorporating Images: Film and the Rival Arts.

Princeton: Princeton University Press.

Sussman, Henry. 2011. Around the Book: Systems and Literacy. New York: Fordham University Press. 